\title{
EFICIÊNCIA DA APLICAÇÃO DO CÓDIGO CONTRA INCÊNDIO E PÂNICO DO CORPO DE BOMBEIROS MILITAR DO ESTADO DE GOIÁS NOS MUNICÍPIOS DE GOIÂNIA E APARECIDA DE GOIÂNIA
}

\author{
Licurgo Borges Winck ${ }^{1}$ \\ Diogo Moreira Fernandes ${ }^{2}$
}

\section{RESUMO}

Com o aumento de obras na engenharia civil nos últimos anos, a questão de segurança em detrimento a outros itens, como o financeiro, passou a ser menosprezada. Mas para que isso não aconteça, colocando os usuários em risco, o Corpo de Bombeiros tem como uma de suas atribuições doutrinar sobre as normas técnicas e atuar como órgão responsável sobre elas. Objetivando avaliar a eficiência do Corpo de Bombeiros Militar de Goiás na prevenção de acidentes que envolvam incêndio e pânico, nos municípios de Goiânia e Aparecida de Goiânia, foi realizado levantamento de dados nos arquivos das seções da instituição que atuam nesse setor na região. Foram realizadas também vistorias com todos os profissionais envolvidos no processo de aprovação e liberação do certificado de conformidade das edificações. Com os dados coletados e compilados, ficou comprovada a eficiência do serviço prestado, visto que mesmo com o aumento da população, a verticalização crescente e o ápice das obras da engenharia civil, o número de ocorrências relacionadas a edificações teve baixo crescimento se comparado com os demais itens avaliados. Assim fica comprovada a eficiência do serviço e mostra o quão eficaz e necessária é a prevenção, através da aplicação das normas técnicas relativas à segurança contra incêndio e pânico.

Palavras-chave: Prevenção, Incêndio, CERCON (Certificado de Conformidade), Corpo de Bombeiros.

\footnotetext{
${ }^{1}$ Tenente do Corpo de Bombeiros Militar do Estado de Goiás. Mestre e Doutor em Ciências Mecânicas pela Universidade de Brasília. E-mail: licurgo2006@gmail.com

${ }^{2}$ Soldado do Corpo de Bombeiros Militar do Estado de Goiás. Graduado em Engenharia Civil pela Pontifícia Universidade Católica de Goiás. E-mail: engenheirodiogofernandes@ gmail.com.
} 


\title{
EFFICIENCY OF THE APPLICATION THE CODE FIRE AND PANIC OF THE MILITARY FIREFIGHTER OF THE GOIÁS STATE IN THE MUNICIPALITY OF GOIÂNIA AND APARECIDA DE GOIÂNIA
}

\begin{abstract}
The increase of works in civil engineering in recent years, the security issue to the detriment of other items, such as financial, became overlooked. But that does not happen, putting users at risk, the Fire Department has as one of its duties indoctrinate on technical standards and act as responsible body on them. To evaluate the effectiveness of the Military Fire Department of Goiás in preventing accidents involving fire and panic in the cities of Goiânia and Aparecida de Goiânia, it was carried out data collection in the archives of the sections of the institution operating in this sector in the region. They were also conducted surveys with all professionals involved in the process of approval and release of the building certificate of conformity. With the collected and compiled data, it was proved the efficiency of service, since even with the increase in population, the increasing vertical integration and the apex of the works of civil engineering, the number of occurrences related to buildings had low growth compared with other evaluated items. Thus it is proven the efficiency of the service and shows how effective and necessary is prevention through the application of technical standards for fire safety and panic.
\end{abstract}

Keywords: Prevention, Fire, Certificate of Conformity, Fire Department.

Artigo recebido em 16/11/16 e Aceito em 26/12/16. 


\section{1 - INTRODUÇÃO}

Institucionalmente o incêndio é entendido como uma "ocorrência indesejável". Como tal, deve ser evitado ou controlado. Cabendo, na sua ocorrência, sanções econômicas ou jurídicas e atribuições de responsabilidade (LUZ NETO, 1995).

Almeida (2002) ressalta que comprovadamente não existe no Brasil uma cultura voltada para a prevenção e preocupação com os fatores de risco, especialmente os riscos de incêndio. Para Ono (2007), a segurança contra incêndio, apesar de ser considerado um dos requisitos básicos de desempenho no projeto, construção, uso e manutenção das edificações, é pouquíssimo contemplada como disciplina no currículo das escolas de engenharia e arquitetura no país.

Verifica-se na prática que a maioria das construtoras preocupam-se com a segurança contra incêndio e pânico somente porque há uma cobrança normativa e legal, refletindo o desinteresse dessas empresas, não havendo interesse real na segurança, conforto, tranquilidade e maior satisfação de seus consumidores.

Para que exista segurança comprovadamente real nas estruturas habitáveis, muitas são as etapas de análise e avaliação, que vai desde a normatização de materiais para usos específicos na engenharia e normatização de procedimento, além da execução de serviços, até a aprovação da edificação para uso com segurança. No entanto, na maioria dos casos observa-se que só existe a efetiva execução dos itens de segurança, por serem passíveis de punição os responsáveis que deixarem de atendê-las.

Dotado de diversas normas técnicas, os Corpos de Bombeiros Militar de todo o país são responsáveis pela elaboração, aplicação e fiscalização da lei que rege a segurança contra incêndio e pânico nas edificações. No Estado de Goiás não é diferente, portanto esse estudo teve como intuito avaliar a eficiência desta instituição na prevenção de incêndio e pânico nos municípios de Goiânia e Aparecida de Goiânia. 


\section{2 - FUNDAMENTAÇÃO TEÓRICA}

O uso de edificações é característica comum a todos, e um dos itens que deve-se observar maior atenção é quanto à segurança que elas oferecem. Esse é um item que não permite falhas, pois pode colocar em risco a vida de seus usuários. A segurança de uma edificação passa pela análise, vistoria, inspeção e aprovação pelos Corpos de Bombeiros Militar, que devem ser efetivos e incisivos, exigindo o cumprimento das leis normativas pertinentes.

A maioria dos acidentes acontece por falta de prevenção, por negligência, imperícia ou imprudência, assim acarretando prejuízos incalculáveis. Somente com as perdas econômicas e de vidas humanas envolvidas em incêndio, é que houve o incremento das pesquisas e investigação nesta área do conhecimento nas últimas décadas (LUZ NETO, 1995).

Cabe ressaltar que em 2005 nos Estados Unidos da América houve 3.677 perdas de vidas humanas de civis em incêndio, 115 bombeiros mortos em serviço, sendo que desses civis $83 \%$ morreram em incêndios residenciais com um valor estimado de perdas de 10,7 milhões de dólares (SEITO ET AL, 2008).

Estatisticamente, com o decorrer do tempo, verifica-se que o crescimento acelerado das grandes cidades, onde se percebe a verticalização avançar a grande escala, contrariamente com o que se verifica em relação aos incêndios e acidentes, justamente devido à melhora da consciência prevencionista, obtida por meio de legislações atualizadas, órgãos de fiscalização comprometidos com a segurança, e o aumento das atividades comunitárias e publicitárias com vistas à prevenção de incêndios e acidentes (CBPMSP, 2011).

Buscando reduzir o número de acidentes ou mesmo mitigar os impactos provocados por acidentes que envolvam incêndio e pânico, constantemente estudos são realizados, normas são criadas e as já existentes evoluem para garantir maior segurança.

No Estado de Goiás as bases legais para tratar de incêndio e pânico iniciaram com a instituição da Lei 9.292/1982, que trata do Código de Segurança Contra 
Revista Científica do Corpo de Bombeiros Militar de Pernambuco

Seção 1 - Artigos Técnico Científicos

Artigo publicado no Vol.03 №06 - Edição de JAN a JUN 2017 - ISSN 2359-4829

Versão on-line disponível em: http://www.revistaflammae.com

Incêndio e Pânico do Estado de Goiás. Esta norma estabelece os requisitos mínimos indispensáveis para a consecução dos fins, levando-se em consideração principalmente a segurança de pessoas, instalações, equipamentos e mercadorias (GOIÁS, 1982). A mais recente atualização, de 07 de novembro de 2014, foi dada pela Portaria do Corpo de Bombeiros Militar № 183/2014, que apresenta 43 normas técnicas referentes à prevenção de acidentes de incêndio e pânico (GOIÁS, 2014).

$A$ adequação da edificação junto às normas técnicas do Corpo de Bombeiros Militar do Estado de Goiás (CBMGO) é obrigatória. O processo de aprovação de um projeto de edificação e liberação do CERCON do CBMGO inicia-se com a avaliação e análise por militares com treinamento nessa função. Sendo essa etapa essencial para que a edificação ofereça toda segurança aos usuários do prédio. $O$ projeto deve atender todas as exigências que a classificação da edificação exigir e caso em análise 0 militar perceba que faltam itens que constam na norma técnica, o documento retorna para serem feitos ajustes pelo projetista responsável. A aprovação só se dá após liberação pelo militar que avaliará o documento, ficando este corresponsável pelo projeto, também carimbando e assinando todas as pranchas aprovadas.

\section{3 - METODOLOGIA}

\section{1 - Área de Estudo}

Para a avaliação da eficiência do CBMGO na prevenção de incêndio e pânico, foram selecionadas unidades da instituição nos municípios de Goiânia e Aparecida de Goiânia (Tabela 1), que executam vistorias nas edificações e analisam projetos, avaliando o cumprimento das normas técnicas pertinentes e liberação do CERCON do CBMGO. 
Revista Científica do Corpo de Bombeiros Militar de Pernambuco Seção 1 - Artigos Técnico Científicos

Artigo publicado no Vol.03 №66 - Edição de JAN a JUN 2017 - ISSN 2359-4829

Versão on-line disponível em: http://www.revistaflammae.com

Tabela 1 - Unidades do CBM-GO selecionadas para a avaliação da eficiência na prevenção de incêndio e pânico nos municípios de Goiânia e Aparecida de Goiânia, Goiás. Fonte: Autoria própria.

\begin{tabular}{|c|c|}
\hline Unidades & Município \\
\hline BM/1 - Estatística e Análise da Informação & Goiânia \\
\hline BM/3 - Planejamento e Gestão Estratégica & Goiânia \\
\hline $\begin{array}{l}\text { BM/7 - Arrecadação, Fiscalização e Atendimento ao } \\
\text { Contribuinte }\end{array}$ & Goiânia \\
\hline Comando de Apoio Logístico - CAL & Goiânia \\
\hline Comando de Operações de Defesa Civil - CODEC & Goiânia \\
\hline Centro Operacional de Bombeiros - COB & Goiânia \\
\hline 1ํㅡ Batalhão Bombeiro Militar - 1ํB BBM & Goiânia \\
\hline $2^{\circ}$ Batalhão Bombeiro Militar - 2으 BBM & Goiânia \\
\hline $7^{0}$ B Batalhão Bombeiro Militar - $7^{\circ}$ BBM & Aparecida de Goiânia \\
\hline 8 Batalhão Bombeiro Militar - 8 BBM & Goiânia \\
\hline
\end{tabular}

\section{2 - Levantamento de Dados}

Nas unidades do CBMGO visitadas foi realizado levantamento de dados nos arquivos das instituições, de onde foram extraídos dados referentes à: registros de ocorrências de acidentes relacionados a incêndio e pânico em edificações de pessoas jurídicas e residências, número de certificados emitidos, projetos analisados, habite-se emitidos, credenciamentos realizados, denúncias recebidas e o número de técnicos responsáveis pela realização de vistorias em edificações nos municípios de Goiânia e Aparecida de Goiânia, no período de 2011 a 2015.

\section{3 - Entrevistas}

Com a intenção de captar o maior número de informações de todas as partes envolvidas na prevenção e combate a acidentes que envolvam incêndio e pânico nos municípios de Goiânia e Aparecida de Goiânia, foram realizadas entrevistas com os vistoriadores, chefe do departamento de projetos e inspeção, responsáveis pelas edificações e usuários de obras. 
As entrevistas foram feitas no período de 01 de março a 30 de abril de 2016. No total foram entrevistadas 19 pessoas, relacionadas por função no processo de prevenção e combate a acidentes que envolvam incêndio e pânico.

\section{4 - Análise de Dados}

Após a realização das visitas, levantamentos de dados e entrevistas, foi feita a compilação das informações obtidas e apresentadas na forma de gráficos e tabelas.

\section{4 - RESULTADOS E DISCUSSÕES}

A corporação militar evoluiu no passar dos anos, e com o objetivo de se ter os dados exatos do tipo de serviço realizado pelos militares, tornaram como padrão, classificar de acordo com a natureza de que se trata o incêndio e através de um campo que relaciona os procedimentos adotados, todas as ocorrências atendidas. A natureza que trata de incêndio foi subclassificada em diversas outras vertentes, levantando lançamentos diários que computaram em dados semanais, mensais e anuais dessas informações.

Separando por edificações comerciais e residenciais, foi compilado em números de ocorrências relativas a acidentes em incêndio e pânico atendidas nos anos de 2011 a 2015 (Tabelas 2 e 3 e Gráficos 1 e 2), e ficou constatado que os números apresentados não acompanharam a crescente dos demais dados. Sendo que mesmo com a entrega de obras acabadas e liberação das edificações para os usuários, nesse período, os números se mantiveram com pequeno crescimento. As Tabelas 2 e 3 mostram a estabilidade nos números de ocorrências, e que comparados com as demais informações, como quantidade do número de servidores que trabalham com vistoria e análise de projetos, mantiveram um ritmo de crescimento discreto, sem expressividade, com pouquíssima relevância. Já o efetivo humano da corporação teve aumento em $36,51 \%$, uma quase estagnação no 
Revista Científica do Corpo de Bombeiros Militar de Pernambuco

Seção 1 - Artigos Técnico Científicos

Artigo publicado no Vol.03 №06 - Edição de JAN a JUN 2017 - ISSN 2359-4829

Versão on-line disponível em: http://www.revistaflammae.com

aumento das ocorrências, devido ao serviço prestado pelos militares que efetivamente atuaram em maior volume de edificações, fiscalizando mais e dando mais segurança aos usuários.

Tabela 2 - Total de ocorrências de acidentes relacionados a incêndio e pânico em edificações de pessoa jurídica, atendidas pelo CBM-GO, nos municípios de Aparecida de Goiânia e Goiânia, no período de 2011 a 2015. Fonte: CBM-GO (2016).

\begin{tabular}{|c|c|c|c|c|c|}
\hline \multirow{2}{*}{ MUNICíPIO } & \multicolumn{5}{|c|}{ ANO } \\
\cline { 2 - 6 } & $\mathbf{2 0 1 1}$ & $\mathbf{2 0 1 2}$ & $\mathbf{2 0 1 3}$ & $\mathbf{2 0 1 4}$ & $\mathbf{2 0 1 5}$ \\
\hline Goiânia & 1294 & 1632 & 1616 & 1906 & 1674 \\
\hline $\begin{array}{c}\text { Aparecida } \\
\text { de Goiânia }\end{array}$ & 350 & 402 & 436 & 466 & 426 \\
\hline Total & $\mathbf{1 6 4 4}$ & $\mathbf{2 0 3 4}$ & $\mathbf{2 0 5 2}$ & $\mathbf{2 3 7 2}$ & $\mathbf{2 1 0 0}$ \\
\hline
\end{tabular}

Tabela 3 - Total de ocorrências de acidentes relacionados a incêndio e pânico em edificações residenciais, atendidas pelo CBM-GO, nos municípios de Aparecida de Goiânia e Goiânia, no período de 2011 a 2015. Fonte: CBM-GO (2016).

\begin{tabular}{|c|c|c|c|c|c|}
\hline \multirow{2}{*}{ MUNICíPIO } & \multicolumn{5}{|c|}{ ANO } \\
\cline { 2 - 6 } & $\mathbf{2 0 1 1}$ & $\mathbf{2 0 1 2}$ & $\mathbf{2 0 1 3}$ & $\mathbf{2 0 1 4}$ & $\mathbf{2 0 1 5}$ \\
\hline Goiânia & 690 & 739 & 750 & 708 & 692 \\
\hline $\begin{array}{c}\text { Aparecida } \\
\text { de Goiânia }\end{array}$ & 240 & 262 & 250 & 280 & 240 \\
\hline Total & $\mathbf{9 3 0}$ & $\mathbf{1 0 0 1}$ & $\mathbf{1 0 0 0}$ & $\mathbf{9 8 8}$ & $\mathbf{9 3 2}$ \\
\hline
\end{tabular}


Revista Científica do Corpo de Bombeiros Militar de Pernambuco Seção 1 - Artigos Técnico Científicos

Artigo publicado no Vol.03 №66 - Edição de JAN a JUN 2017 - ISSN 2359-4829

Versão on-line disponível em: http://www.revistaflammae.com

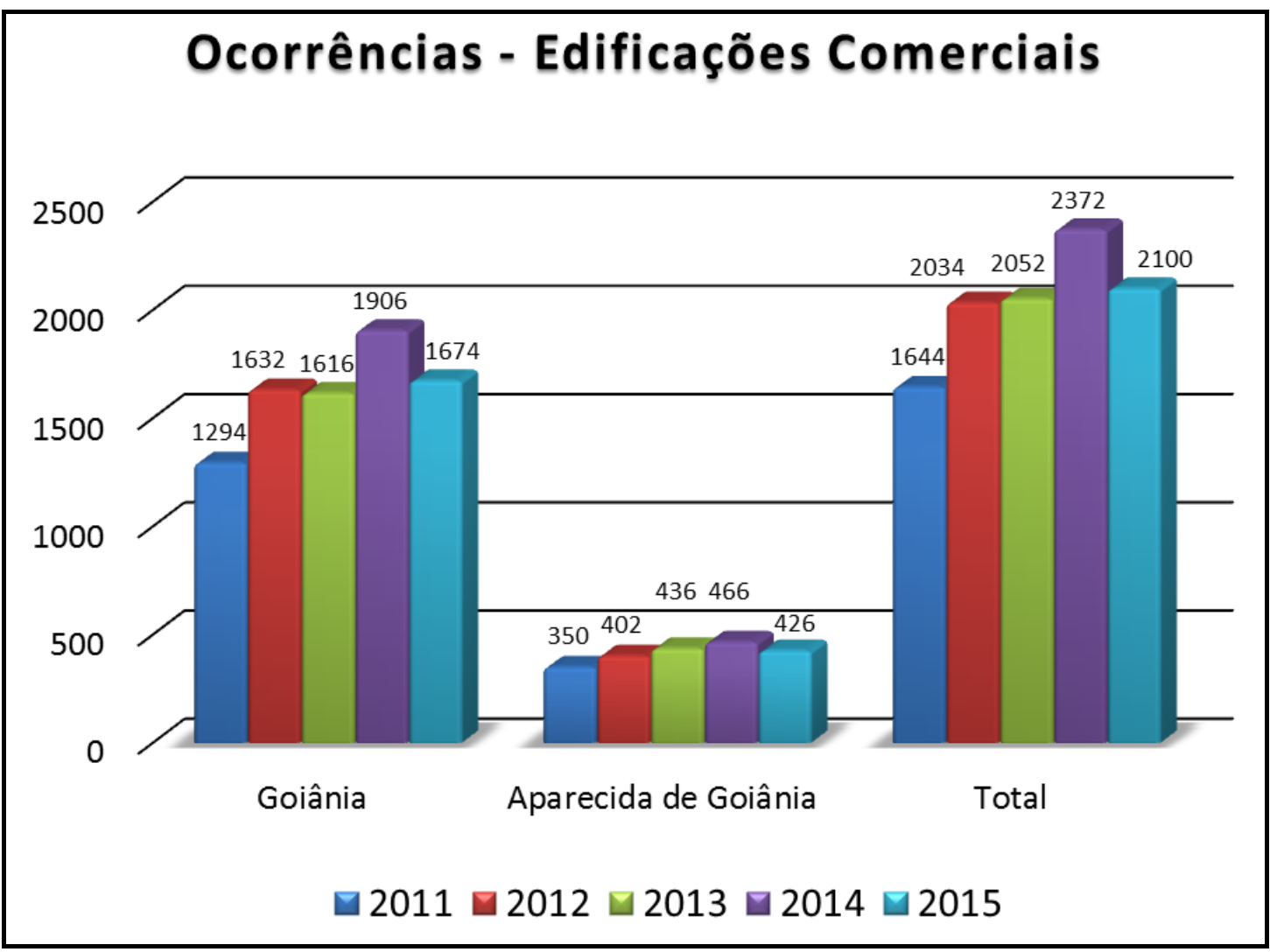

Gráfico 1 - Número de Ocorrências em Edificações Comerciais. Fonte: CBM-GO (2016). 
Revista Científica do Corpo de Bombeiros Militar de Pernambuco Seção 1 - Artigos Técnico Científicos

Artigo publicado no Vol.03 №06 - Edição de JAN a JUN 2017 - ISSN 2359-4829

Versão on-line disponível em: http://www.revistaflammae.com

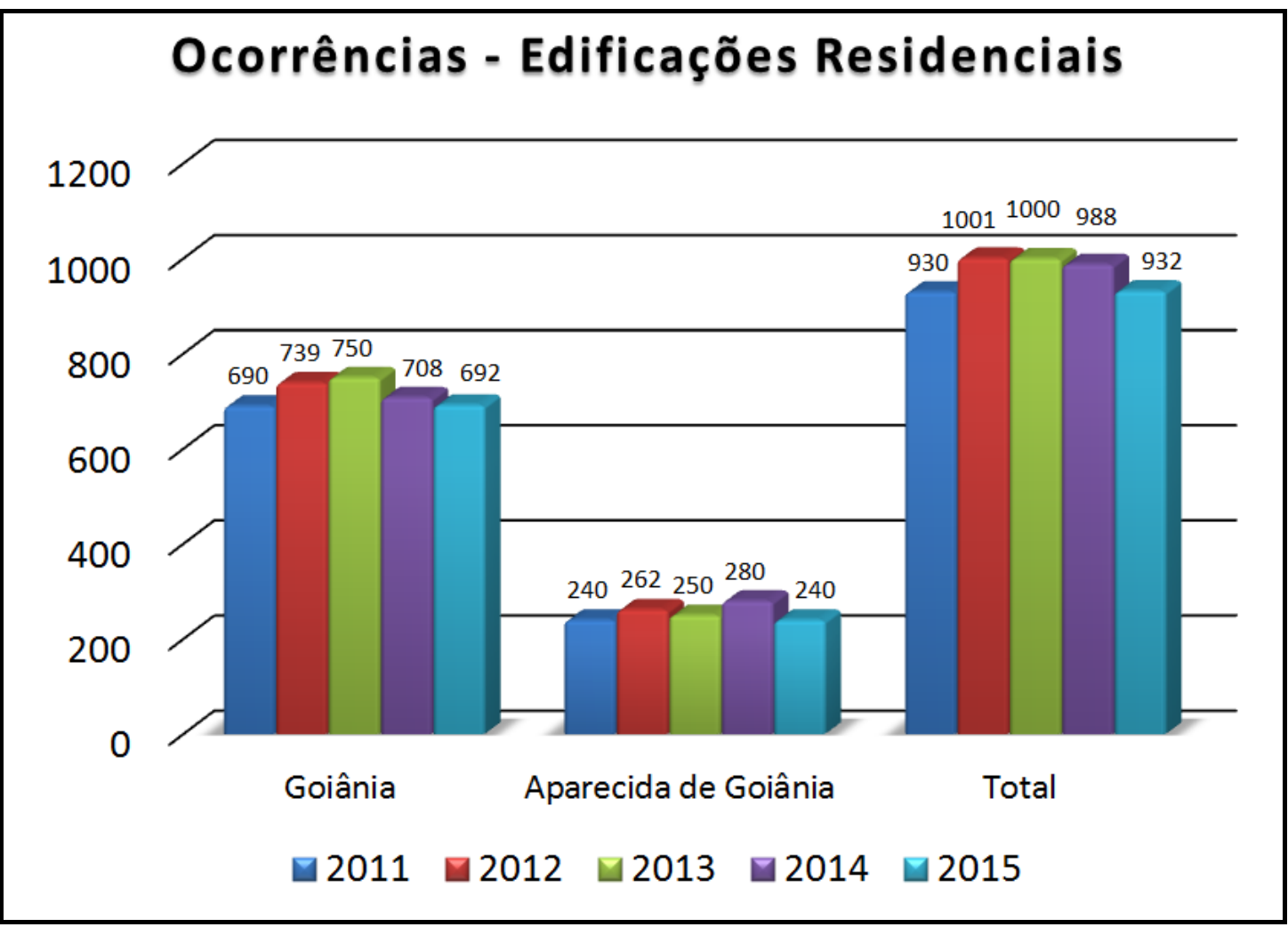

Gráfico 2 - Número de Ocorrências em Edificações Residenciais Fonte: CBM-GO (2016).

Um fator preponderante para que todos esses números de ocorrências entrassem com relativa estagnação, foi o aumento gradativo do efetivo nos departamentos responsáveis pelas inspeções e análises de projetos, pois o efetivo militar pode fiscalizar maior volume de edificações, analisar mais projetos, oferecer maior segurança aos usuários, e conceder com isso maior quantidade de certificados aprovados. A Tabela 4 trata do quantitativo de vistoriadores nas unidades analisadas e mostra um crescimento no material humano oferecido ao interesse público para atender e dar segurança aos comércios e residências de Goiânia e Aparecida de Goiânia. 
Revista Científica do Corpo de Bombeiros Militar de Pernambuco

Seção 1 - Artigos Técnico Científicos

Artigo publicado no Vol.03 №06 - Edição de JAN a JUN 2017 - ISSN 2359-4829

Versão on-line disponível em: http://www.revistaflammae.com

Tabela 4 - Total de militares nos departamentos de inspeção e análise de projetos, nos municípios de Aparecida de Goiânia e Goiânia, no período de 2011 a 2015. Fonte: CBM-GO (2016).

\begin{tabular}{|l|c|c|c|c|c|}
\hline \multirow{2}{*}{ Documento } & \multicolumn{4}{|c|}{ ANO } \\
\cline { 2 - 6 } & 2011 & 2012 & 2013 & 2014 & 2015 \\
\hline Vistoriadores & 63 & 68 & 76 & 87 & 86 \\
\hline
\end{tabular}

Com esse acréscimo de militares, mais projetos puderam ser analisados e aprovados, como trata a Tabela 5 e verifica-se no Gráfico 3, aumentando em duas vezes esse quantitativo de 2011 a 2015, e quando comparado ao total de ocorrências, pode ser tratado como um dos itens que interferem no pouco crescimento desses números, pois mais edificações passaram por trabalhos da corporação e quando aprovadas oferecem a segurança necessária a toda população.

Tabela 5 - Total de projetos aprovados pelo CBM-GO, nos municípios de Aparecida de Goiânia e Goiânia, no período de 2011 a 2015. Fonte: CBM-GO (2016).

\begin{tabular}{|c|c|c|c|c|c|}
\hline \multirow{2}{*}{ Documento } & \multicolumn{5}{|c|}{ ANO } \\
\hline & 2011 & 2012 & 2013 & 2014 & 2015 \\
\hline $\begin{array}{l}\text { Projetos } \\
\text { aprovados }\end{array}$ & 1.444 & 1.441 & 1.286 & 998 & 2.796 \\
\hline
\end{tabular}


Revista Científica do Corpo de Bombeiros Militar de Pernambuco Seção 1 - Artigos Técnico Científicos

Artigo publicado no Vol.03 №66 - Edição de JAN a JUN 2017 - ISSN 2359-4829

Versão on-line disponível em: http://www.revistaflammae.com

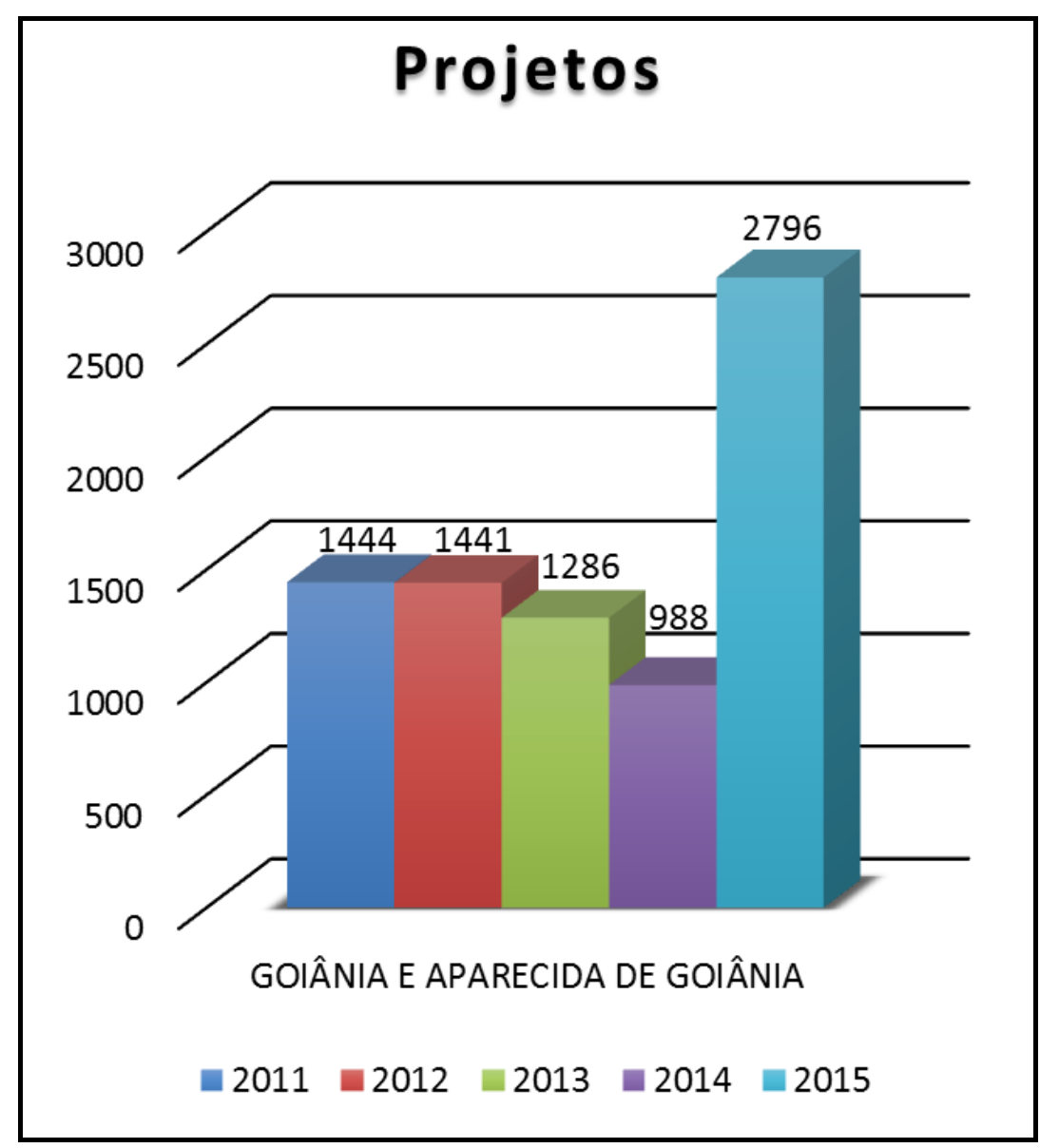

Gráfico 3 - Número de Projetos Aprovados

Com a elevação numérica do efetivo militar, mais vistorias foram realizadas e habite-se liberados (Tabela 6), o que comprova a crescente na quantidade de obras entregues no decorrer dos anos avaliados e que mesmo com esse aumento, a proporção das ocorrências relativas a incêndio e pânico não acompanhou esse ritmo, demonstrando assim que o serviço prestado pela corporação teve eficiência, liberando para que os usuários pudessem, com segurança, usufruir das edificações.

Tabela 6 - Total de habite-se liberados pelo CBM-GO, nos municípios de Aparecida de Goiânia e Goiânia, no período de 2011 a 2015. Fonte: CBM-GO (2016).

\begin{tabular}{|c|r|r|r|r|r|}
\hline \multirow{2}{*}{ Documento } & \multicolumn{4}{|c|}{ ANO } \\
\cline { 2 - 6 } & $\mathbf{2 0 1 1}$ & 2012 & 2013 & 2014 & 2015 \\
\hline Habite-se & 279 & 267 & 199 & 148 & 519 \\
\hline
\end{tabular}


Revista Científica do Corpo de Bombeiros Militar de Pernambuco Seção 1 - Artigos Técnico Científicos

Artigo publicado no Vol.03 №06 - Edição de JAN a JUN 2017 - ISSN 2359-4829

Versão on-line disponível em: http://www.revistaflammae.com

Como aumentaram as edificações fiscalizadas, e estando grande parte em conformidade, seguras e legalmente documentadas, o números de denúncias averiguadas (Tabela 7 e Gráfico 4), sofreram decréscimo no ano de 2015, sinalizando a evolução dos trabalhos desenvolvidos, não deixando oportunidades para que edificações desenvolvam suas atividades em desacordo com as normas técnicas do CBMGO.

Tabela 7 - Total de denúncias avaliadas pelo CBM-GO, nos municípios de Aparecida de Goiânia e Goiânia, no período de 2011 a 2015. Fonte: CBM-GO (2016).

\begin{tabular}{|c|c|c|c|c|c|}
\hline \multirow{2}{*}{ Documento } & \multicolumn{4}{|c|}{ ANO } \\
\cline { 2 - 6 } & $\mathbf{2 0 1 1}$ & $\mathbf{2 0 1 2}$ & $\mathbf{2 0 1 3}$ & $\mathbf{2 0 1 4}$ & $\mathbf{2 0 1 5}$ \\
\hline Denúncias & 272 & 2.220 & 2.667 & 4.099 & 131 \\
\hline
\end{tabular}


Revista Científica do Corpo de Bombeiros Militar de Pernambuco Seção 1 - Artigos Técnico Científicos

Artigo publicado no Vol.03 №66 - Edição de JAN a JUN 2017 - ISSN 2359-4829

Versão on-line disponível em: http://www.revistaflammae.com

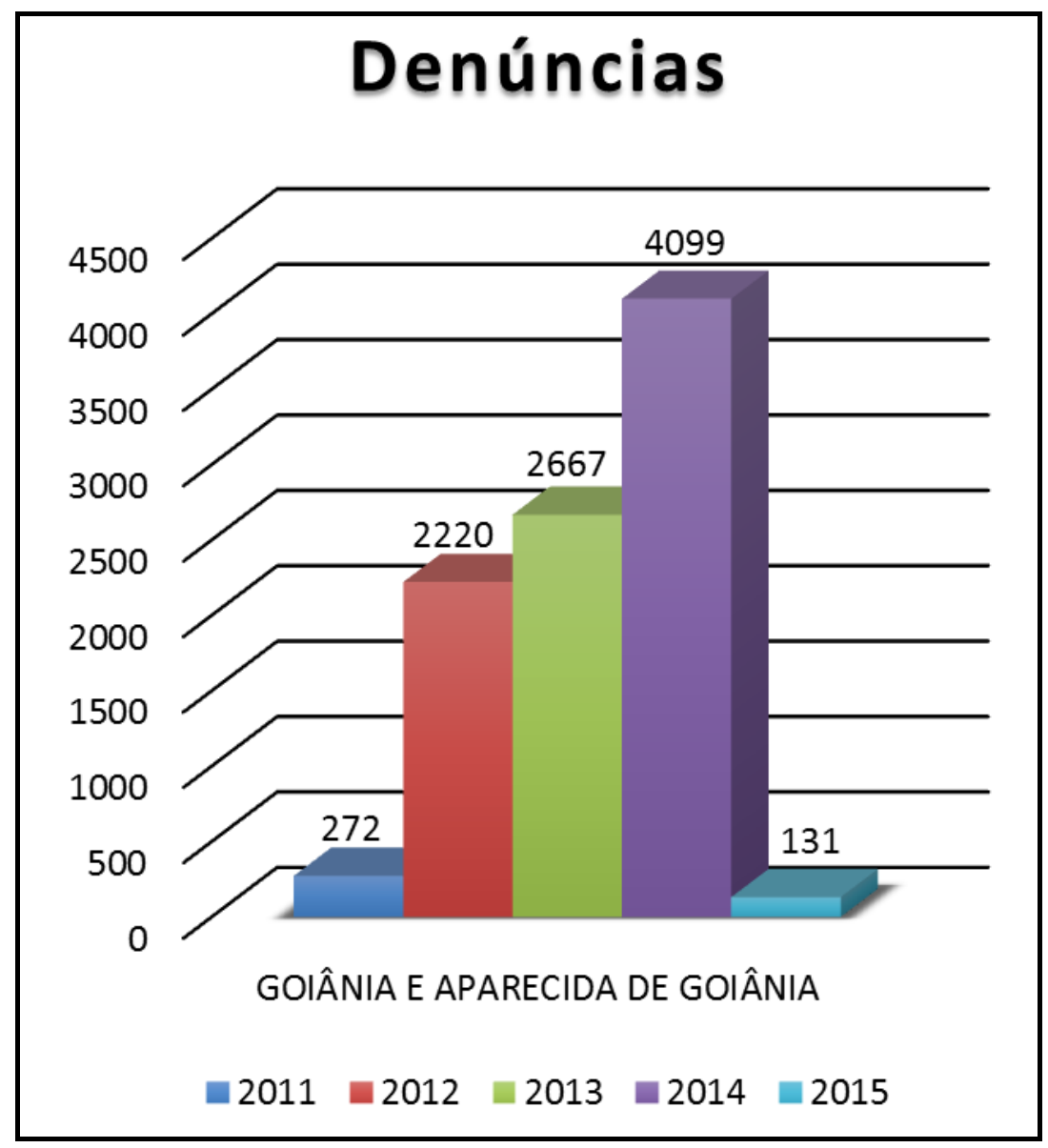

Gráfico 4 - Número de Denúncias

A eficiência fica evidenciada com o aumento de $359,67 \%$ de CERCON emitidos entre os anos de 2011 a 2015 , saindo de 12.281 no primeiro ano avaliado para 56.453 documentos no último ano em levantamento, conforme observa-se no Gráfico 5. 
Revista Científica do Corpo de Bombeiros Militar de Pernambuco

Seção 1 - Artigos Técnico Científicos

Artigo publicado no Vol.03 №66 - Edição de JAN a JUN 2017 - ISSN 2359-4829

Versão on-line disponível em: http://www.revistaflammae.com

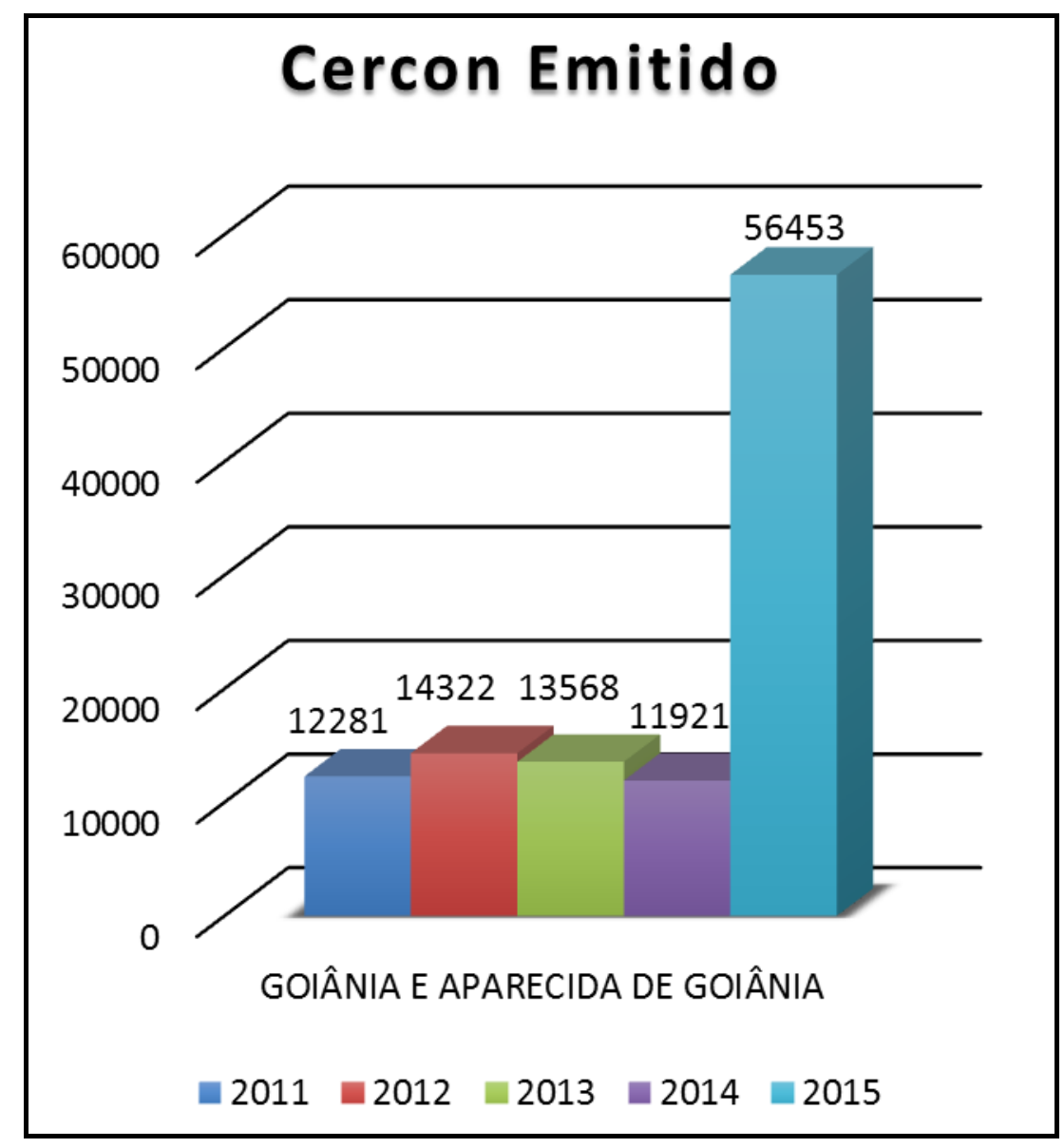

Gráfico 5 - Número de Cercon Emitido

Com o passar dos anos, o cruzamento dos dados, de tipos e número de ocorrências, estudos desenvolvidos nas edificações e segundo os profissionais do ramo, a corporação assumiu que não há necessidade de realizar vistoria em todas as edificações de pessoas jurídicas existentes, e aos poucos, desde 2011, vem-se estudando critérios para certificação de edificações que atendam alguns requisitos básicos, sem a necessidade da visita do vistoriador. Este documento de liberação sem a necessidade de vistoria no local é conhecido como Certificação Prévia, e é fornecida a todas as edificações com área menor que $200 \mathrm{~m}^{2}$ e que não possuam riscos citados em norma técnica. Dessa forma, de 2011 a 2014 nenhuma edificação era liberada sem a visita de um vistoriador, já em 2015 o número de edificações certificadas sem a necessidade de vistoria foi de 9.557. Esta forma de atuação 
Revista Científica do Corpo de Bombeiros Militar de Pernambuco Seção 1 - Artigos Técnico Científicos

Artigo publicado no Vol.03 №06 - Edição de JAN a JUN 2017 - ISSN 2359-4829

Versão on-line disponível em: http://www.revistaflammae.com

aumentou a disponibilidade dos vistoriadores e permitiu que os militares focassem nas edificações de maior risco e com maiores necessidades, otimizando os serviços e fiscalizando mais unidades em Goiânia e Aparecida de Goiânia.

Toda empresa interessada em trabalhar com itens de prevenção e combate a incêndio, como revenda e manutenção de extintores portáteis, necessitam de credenciamento junto ao corpo de bombeiros. Esta é uma forma de atestar que todas operam de maneira legal e atendem aos princípios para prestarem os serviços pertinentes ao ramo, dando maior segurança aos que necessitarem de seus trabalhos. Em 2011 eram apenas 30 empresas credenciadas, já em 2015 este número alcançou 115 nos municípios de Goiânia e Aparecida de Goiânia, conforme observado no Gráfico 6.

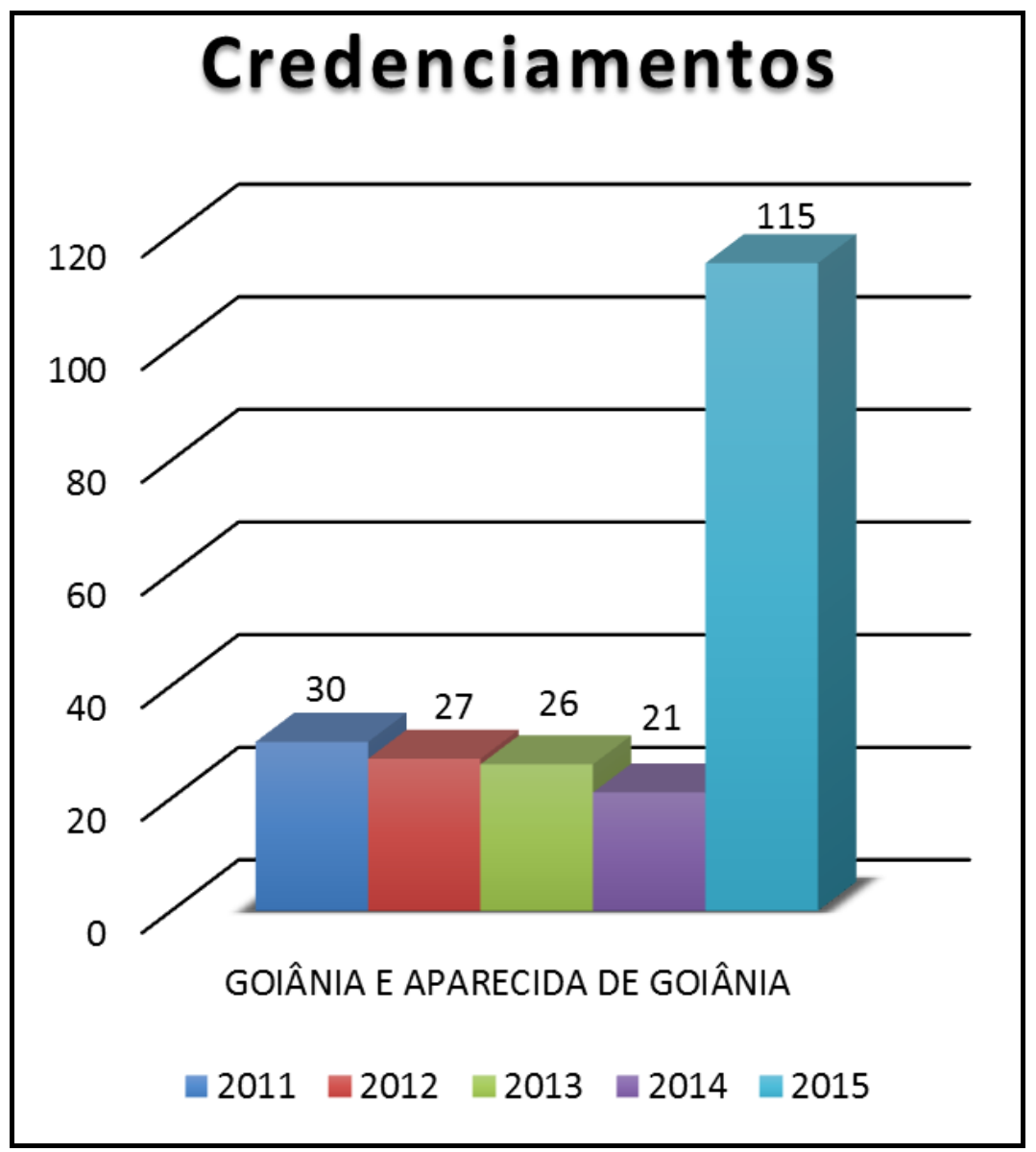

Gráfico 6 - Número de Credenciamentos Realizados 
Com o crescente número de cadastros na corporação, a facilidade de acesso a itens de segurança aumenta, melhorando os comércios que buscam atender com mais rapidez aos itens de segurança exigidos pelo corpo de bombeiros, facilitando o trabalho dos militares que fazem as inspeções nas edificações atendidas por essas empresas credenciadas.

\section{1 - Entrevistas}

\subsection{1 - Chefes das seções}

Segundo o chefe do departamento de análise de projetos e inspeções, quando questionado sobre a importância do CERCON, foi informado ser essenciais para garantir que a edificação passou por avaliação dos vistoriadores e atende todas as normas de segurança contra incêndio e pânico.

Sobre a formação acadêmica dos analistas de projeto e vistoriadores, disseram não existir área específica, ou graduação direcionada para nenhuma das funções. O que Ihes confere tal atribuição é o treinamento interno, fornecido pela corporação, sendo que para ser analista é obrigatório ser do quadro de oficiais, e para vistoriador ser do quadro de praças. Os oficiais passam por curso de formação com período de duração de dois anos, saindo aptos para realizar inspeção e analise de projetos, através do Curso de Análise de Projetos e Inspeção em Edificações e Áreas de Risco (CAPIEAR). As praças passam por treinamento denominado Curso de Inspeção em Edificações e Áreas de Risco (CIEAR), para a partir daí estarem aptos a aplicar as normas técnicas pertinentes a cada vistoria.

Os chefes das seções indagados sobre o principal foco dos departamentos, informaram que tem como objetivo, a prevenção através da aplicação das leis e normas técnicas relativas à segurança contra incêndio e pânico. 
Revista Científica do Corpo de Bombeiros Militar de Pernambuco Seção 1 - Artigos Técnico Científicos

Artigo publicado no Vol.03 №06 - Edição de JAN a JUN 2017 - ISSN 2359-4829

Versão on-line disponível em: http://www.revistaflammae.com

\subsection{2 - Analistas de projeto}

Explanando sobre as análises de projeto, os profissionais explicaram que os documentos são distribuídos por todas as unidades corporativas, de acordo com a localização do empreendimento. Quando avaliados, adequações são lançadas no sistema para que sejam atendidas e somente após o procedido com estas questões sendo sanadas, retorna ao bombeiro responsável, para que este finalize com a aprovação das pranchas em análise. Normalmente, o trabalho é realizado por um único militar, saindo a aprovação com a assinatura deste que fez a avaliação.

\subsection{3 - Vistoriadores}

Os vistoriadores informaram que os treinamentos são relativamente poucos e que os conhecimentos são adquiridos na grande maioria das vezes pelo próprio interesse de cada militar em estudar as normas técnicas. Mas que se sentem capacitados em desempenhar suas funções, mesmo com esta problemática.

Também foi repassado que existem classes de vistorias e que nem todos os processos tem necessidades de serem visitados, sendo esses casos denominados como certificação prévia, tendo no máximo $200 \mathrm{~m}^{2}$ de área e não possuindo riscos que necessitem serem analisados. Já os casos que possuam riscos que não classifiquem como prévia, ou com área superior a esta metragem, necessitam obrigatoriamente de vistoria, sendo realizadas com mais de um militar se possuírem mais de $750 \mathrm{~m}^{2}$.

\subsection{4 - Usuários da edificação}

Segundo proprietários de empresas nas cidades de Goiânia e Aparecida de Goiânia, é de suma importância tanto a análise de projeto quanto a vistoria, pois com esse auxílio da corporação é que seus comércios estão respaldados de futuros acidentes que possam acontecer. A vistoria é solicitada justamente para que os 
vistoriadores façam uma varredura em todo metro quadrado construído e libere o certificado de conformidade, assegurando que o empreendimento está atendendo todos os itens de segurança exigidos pelas normas.

Sobre o certificado, para eles, ter o documento em mãos atesta a segurança da edificação, sendo este documento exigido também por vários órgãos que autorizam o funcionamento e uso, inclusive para o ressarcimento após sinistro pela seguradora.

Uma das questões que pode ser melhorada, segundo os próprios comerciantes, é a unificação da forma de abordagem da corporação pelos vistoriadores junto às pessoas jurídicas. Isto para que cada militar que vá realizar a análise da edificação, as adequações não sejam discrepantes umas das outras.

\section{5 - CONCLUSÕES}

É real a necessidade da vistoria para avaliar o cumprimento dos dispositivos das normas técnicas, visto que, com o aumento do número de vistoriadores e melhor direcionamento das inspeções nas obras, comércios e edificações que oferecem riscos, é que efetivamente ocorreram resultados no número de acidentes e ocorrências relativas a incêndio e pânico, fazendo com que a quantidade não acompanhasse o crescente ritmo das construções e abertura de comércios, se mantendo relativamente estagnada com pequeno crescimento, de forma não exorbitante quando comparada a evolução da engenharia civil nesse período avaliado.

A evolução associada ao aumento dos números de inspeções, certificados emitidos, projetos analisados, habite-se liberados, assimilado a reduções do número de denúncias e a relativa dormência da quantidade de ocorrências relacionadas a incêndio e pânico, comprovam a eficiência da corporação no quesito prevenção da área técnica.

Aumentando o número de Certificações prévias, que são as de baixíssimo risco e índices de acidentes, que não necessitam de inspeção, diminuiu o serviço e 
liberou uma quantidade maior de vistoriadores, e assim permitiu maior efetividade dos trabalhos realizados. A crescente de empresas credenciadas, que trabalham com produtos de prevenção como extintores de incêndio, possibilitou maior acesso dos comerciantes aos itens de segurança e a informações das normas técnicas, dando celeridade às vistorias, pois o conhecimento das empresas com os itens facilita a proteção dos comércios e deixa o estabelecimento previamente organizado, viabilizando ainda mais o trabalho do vistoriador.

O aumento do efetivo militar e todos os serviços ofertados pela corporação acompanharam essa crescente; elevando o quantitativo de vistorias realizadas, os projetos analisados, além dos certificados emitidos como pré-requisito para liberação de habite-se por parte das prefeituras desses municípios impossibilitando a abertura de novas edificações sem fiscalização. E por conta dessas cobranças, surgiu no mercado uma procura por produtos para adequar as exigências de segurança que atendam ao corpo de bombeiros, e empresas passaram a se credenciar para atender esse nicho de mercado. Visto que todo esse aumento nas questões de fiscalização, inspeção e analise; fica evidente que a baixa crescente, quase estagnação no número de ocorrências, pode ser vinculada a esta mudança.

Cabe ressaltar e como apontado por CBPMSP (2011), pode-se destacar que a questão técnica é de suma importância para a estagnação das ocorrências envolvendo incêndios, porém com aspectos importantes que devem ser levados em consideração, tais como: aumento das atividades comunitárias e publicitárias com vistas à prevenção de incêndios e acidentes.

Além disso, as críticas apontadas pelos vistoriadores em relação à baixa quantidade de treinamentos ofertados pela corporação refletiram na oferta de quatro turmas com 25 alunos somente no ano de 2016 do Curso de Inspeção em Edificações e Áreas de Risco (CIEAR) para as praças que atuam nesta área e não tinham a oportunidade de se especializar. Esses treinamentos refletem de maneira positiva a padronização da atuação e realização das inspeções para reduzir um dos principais questionamentos dos usuários contribuintes, que seria a discrepância na forma de inspecionar as edificações por parte dos vistoriadores. 
Revista Científica do Corpo de Bombeiros Militar de Pernambuco Seção 1 - Artigos Técnico Científicos

Artigo publicado no Vol.03 №06 - Edição de JAN a JUN 2017 - ISSN 2359-4829

Versão on-line disponível em: http://www.revistaflammae.com

Por fim, a contiguidade e constância no número de ocorrências relativas a incêndio e pânico em edificações residenciais e comerciais, sem grandes progressos e ascensões, está diretamente relacionada à prevenção prestada devido ao aumento da quantidade de pessoas nos departamentos de vistoria e análise de projetos, como resultado demonstrado ao longo do artigo, comprovando assim a eficiência do serviço provido pela corporação.

\section{REFERÊNCIAS}

ALMEIDA Junior, I. Análise de risco de incêndio em espaço urbano revitalizados: Uma abordagem no Bairro de Recife. Dissertação de Mestrado, UFPE, 2002.

CORPO DE BOMBEIRO MILITAR DE GOIÁS. Norma Técnica, de 01 de outubro de 2014. Disponível em: < http://www.bombeiros.go.gov.br/legislacao/normastecnicas/nt-2014-segunda-edicao.html>. Acesso em: 05 novembros 2015.

GOIÁS. Lei no 9.292, de 24 de novembro de 1982. Diário Oficial do Estado de Goiás. Disponível em: <http://www.gabinetecivil.goias.gov.br/pagina_leis.php?id=6874>. Acesso em: 23 outubro 2015.

GOIÁS. Portaria no 183, de 07 de novembro de 2014. Atualização Das Normas Técnicas Da Corporação. Goiás, p. 1-3, Comandante de Operações de Defesa Civil do Corpo de Bombeiros Militar do Estado de Goiás.

LUZ NETO. Manual ativo das condições de segurança contra incêndio. Brasília: Ministério da Saúde, 1995.

ONO, R. Parâmetro de garantia de qualidade de projeto de segurança contra incêndio em edifícios altos. Ambiente Construído. Porto Alegre, v.7, n.1 p. 97113. Jan./mar. 2007.

SEITO, A. I.; GIL, A. A.; PANNONI, F. D.; ONO, R.; SILVA, S. B.; CARLO, U. D.; SILVA, V. P. A Segurança contra incêndio no Brasil. São Paulo, 2006.

CBPMSP. Governo do Estado de São Paulo. Corpo de Bombeiros. Cartilha de Orientações Básicas. Noções de Prevenção Contra Incêndio. São Paulo, 2011. 